\title{
基于街景测量的南昌市行道树结构特征与健康状况 研究
}

\author{
梁陈涛 ${ }^{1}$, 杨艳波 ${ }^{1}$, 田盼立 ${ }^{1}$, 肖 路 $^{2}$, 王慧梅 ${ }^{1}$, 王文杰 ${ }^{1,2, *}$ \\ 1 森林植物生态学教育部重点实验室,东北林业大学化学化工与资源利用学院, 哈尔滨 150040 \\ 2 中国科学院东北地理与农业生态研究所,长春 130102
}

摘要:行道树作为城市绿地系统的网络和骨架,在城市居民生活中发挥着无可替代的作用。快速准确的掌握城市行道树的结构 特征和健康状况,有利于城市森林建设与管理,进而提升其生态服务功能。基于百度街景平台,通过街景测树法对南昌市的 963 个样方,共计 26727 株行道树展开调查。测量内容包括行道树大小指标(树高、胸径、冠下高和冠幅)、健康状况(支架比例、 枯稍比例、叶色不健康比例和死亡比例) 和植被垂直结构配置情况; 并且探究了不同行政区和不同城市化强度 (环城道路发展 下的城乡梯度)下行道树的空间分布特征。结果表明:(1) 南昌市行道树小树比例较高:胸径在 $10-20 \mathrm{~cm}$ 的占 $65 \%$,冠下高在 1.5-2.5 m 间的占 76\%, 树高在 4-8 $\mathrm{m}$ 间的占 71\%, 冠幅在 2-6 $\mathrm{m}$ 间的占 $76 \%$; 行道树生长整体表现为健康,各指标所占比例 较小, 但是叶片健康较差; $35 \%$ 的样地无叶色不健康, $77 \%$ 的样地无支架, $76 \%$ 的样地无枯梢, $93 \%$ 的样地无死亡; 植被垂直结构 配置状况良好, 以乔-灌-草复合结构为主 (比重为 75\%); (2) 在空间分布上,不同行政区行道树大小指标和垂直结构配置上差 异显著、健康状况 (支架比例和叶色不健康比例) 均表现显著性差异 $(P<0.05)$; 不同环路行道树大小指标存在显著差异, 表现为 1 环 $>2$ 环 $>3$ 环, 垂直结构从内环到外环更为复杂, 配置等级为 1 环 $<2$ 环 $<3$ 环, 不同环路行道树健康状况 (支架比例和叶色不 健康比例 $)$ 表现显著性差异 $(P<0.05)$ 。综上所述, 南昌市行道树整体健康状况良好, 行道树个体较小, 而且以复层结构为主, 本 研究基于百度街景对南昌市行道树结构特征和健康状况进行比较全面的评价, 为南昌市今后城市行道树的规划和管理提供了 基础数据支持。

关键词: 行道树;百度街景; 垂直结构;树木大小;森林健康

\section{Structural characteristics and health status of roadside trees in Nanchang City, China from Baidu Street View-based measurements}

\author{
LIANG Chentao $^{1}$, YANG Yanbo ${ }^{1}$, TIAN Panli ${ }^{1}$, XIAO Lu ${ }^{2}$, WANG Huimei ${ }^{1}$, WANG Wenjie ${ }^{1,2, *}$ \\ 1 Key Laboratory of Forest Plant Ecology, College of Chemistry, Chemical Engineering and Resource Utilization, Northeast Forestry University, Harbin \\ 150040, China \\ 2 Northeast Institute of Geography and Agroecology, Chinese Academy of Science, Changchun 130102, China
}

\begin{abstract}
As the network and skeleton of urban green space system, roadside trees play an irreplaceable role in urban residents' life. Rapid and accurate grasp of the structural characteristics and health status of urban roadside trees is conducive to the construction and management of urban forest, thus improving its ecological service function. Based on the Baidu Street View platform, this study investigated 963 quadrats, a total of 26,727 roadside trees, in Nanchang by street view tree measurement method. Measures included indicators of street tree sizes (diameter at breast height ( DBH),

基金项目: 国家自然基金重点项目(41730641); 国家自然基金面上项目(31670699); 龙江学者支持计划( T201702); 黑龙江省头雁团队支持计划 收稿日期: 2020-11-24; 网络出版日期:2021-09-09

* 通讯作者 Corresponding author.E-mail: wangwenjie@ iga.ac.cn
\end{abstract}


underbranch height $(\mathrm{UBH})$, tree height ( TH ) and canopy size ( CS )), health status ( the proportion of Tripodsupporting, the proportion of Dieback, the proportion of Non-greenness leaf color and the proportion of Death trees ), and vertical structure configuration of vegetation. Moreover, the spatial distribution characteristics of road trees under different administrative regions and different urbanization intensities ( urban and rural gradient under the development of ring roads) were explored. The results showed that: (1) there was a high proportion of small trees in Nanchang: DBH of $10-20 \mathrm{~cm}$ accounted for $65 \%$, UBH of $1.5-2.5 \mathrm{~m}$ accounted for $76 \%$, TH of 4-8 m accounted for 71\%, CS of 2-6 m accounted for $76 \%$. The overall performance of the growth of street trees was healthy, the proportion of each index was small, but the leaf health was poor. In 35\% of the plots, no leaf color was unhealthy, 77\% of the plots had no Tripod-supporting, 76\% of the plots had no Dieback and $93 \%$ of the plots had no death. The vertical structure of vegetation was in good condition, mainly composed of arbor-shrub-herb (75\% of the sample land). (2) In terms of spatial distribution, there are significant differences in the sizes index and vertical structure configuration of road trees in different administrative areas, and significant differences in health status ( proportion of Tripod-supporting and proportion of Non-greenness leaf color) $(P<$ $0.05)$. There were urban-rural differences in the size index of road trees in different ring-road areas, which are manifested as $1^{\text {st }}$ ring $>2^{\text {nd }}$ ring $>3^{\text {rd }}$ ring, the vertical structure of the outer ring is more complex, configuration grade is $1^{\text {st }}$ ring $<2^{\text {nd }}$ ring $<3^{\text {rd }}$ ring. There were significant differences in the health status of different ring-road (proportion of Tripod-supporting and proportion of Non-greenness leaf color $)(P<0.05)$. To sum up, the overall health status of the roadside trees in Nanchang is good, the individual of the roadside trees is small, and they are mainly composed of multiple layers. Based on the Baidu Street View, this study makes a relatively comprehensive evaluation of the structural characteristics and health status of the roadside trees in Nanchang, which provides basic data support for the planning and management of the urban roadside trees in Nanchang in the future.

Key Words : roadside tree; Baidu Street View; vertical structure; tree sizes; forest health

行道树是城市绿化基础设施的重要组成部分,具有减少噪音、改善微气候、净化空气、美化城市等重要的 作用 ${ }^{[1-2]}$ 。行道树大小、结构和健康状况直接影响城市环境和生态服务功能 (固碳、降尘等) 以及城市观光价 值。最大化提升行道树生态服务功能已经成为城市绿地建设和管理一个重点, 而明确行道树结构特征与健康 状况是重要基础 ${ }^{[3]}$ 。在获取城市行道树基础数据时, 在更大、高密度区域准确树木测量才能保证准确生态功 能评价。

随着网络大数据技术的发展, 在线三维街景地图已广泛用于城市环境研究 ${ }^{[4-7]}$ 。我们课题组前期开发了 街景照片测量法用于行道树胸径、树高、冠下高和冠幅的方法,并在 Urban Forestry Urban Greening 上发表 ${ }^{[8]}$ 。 也有人用于量化与叶面积相关的冠层盖度 ${ }^{[4]}$ 、遮荫作用 ${ }^{[9]}$ 。街景测量法与传统实地调查相比街景调查具有 高效、节约成本等优点,为城区大面积、高密度的树木测量提供了基础。

南昌是我国长江中游地区重要的中心城市, 总人口 560 万。针对南昌市城市森林及行道树研究多集中在

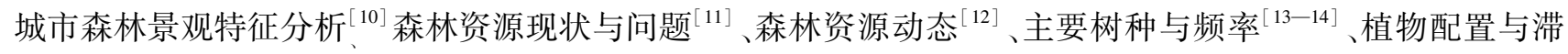
尘功能 ${ }^{[15]}$ 。这些研究为南昌市城市森林功能提升奠定了良好的基础。基于网络大数据, 针对树木大小、健康 与垂直分布大范围、多指标更加全面性评价和空间图示,将更有助于基于数据的南昌市城市森林管理提升。

基于上述, 本研究通过百度街景平台的网络街景测树法对南昌市行道树的结构特征和健康状况展开全城 市区域的详细调查、测定与空间分布绘图, 旨在对南昌市的城市行道树建设进行科学、全面评价, 为南昌市未 来城市绿化基础设施提供数据支持。

\section{1 研究地点与研究方法}

\section{1 研究区域}

南昌市是江西省的省会城市。南昌地处江西中部偏北, 赣江、抚河下游, 鄱阳湖西南岸, 位于东经 
$115^{\circ} 27^{\prime}-116^{\circ} 35^{\prime}$ 、北纬 $28^{\circ} 10^{\prime}-29^{\circ} 11^{\prime}$ 之间 ${ }^{[16]}$, 历年平均气温在 $17.1-17.8^{\circ} \mathrm{C}$, 全年降水量 $1567.7-1654.7$ $\mathrm{mm}^{[17]}$ 。本研究选取南昌市三环以内的区域作为实验调查样地,共包括 7 个行政区,分别是:西湖区、青云谱 区、青山湖区、南昌县、东湖区、新建县和湾里区,如图 1 所示,总面积为 $987 \mathrm{~km}^{2}$ 。

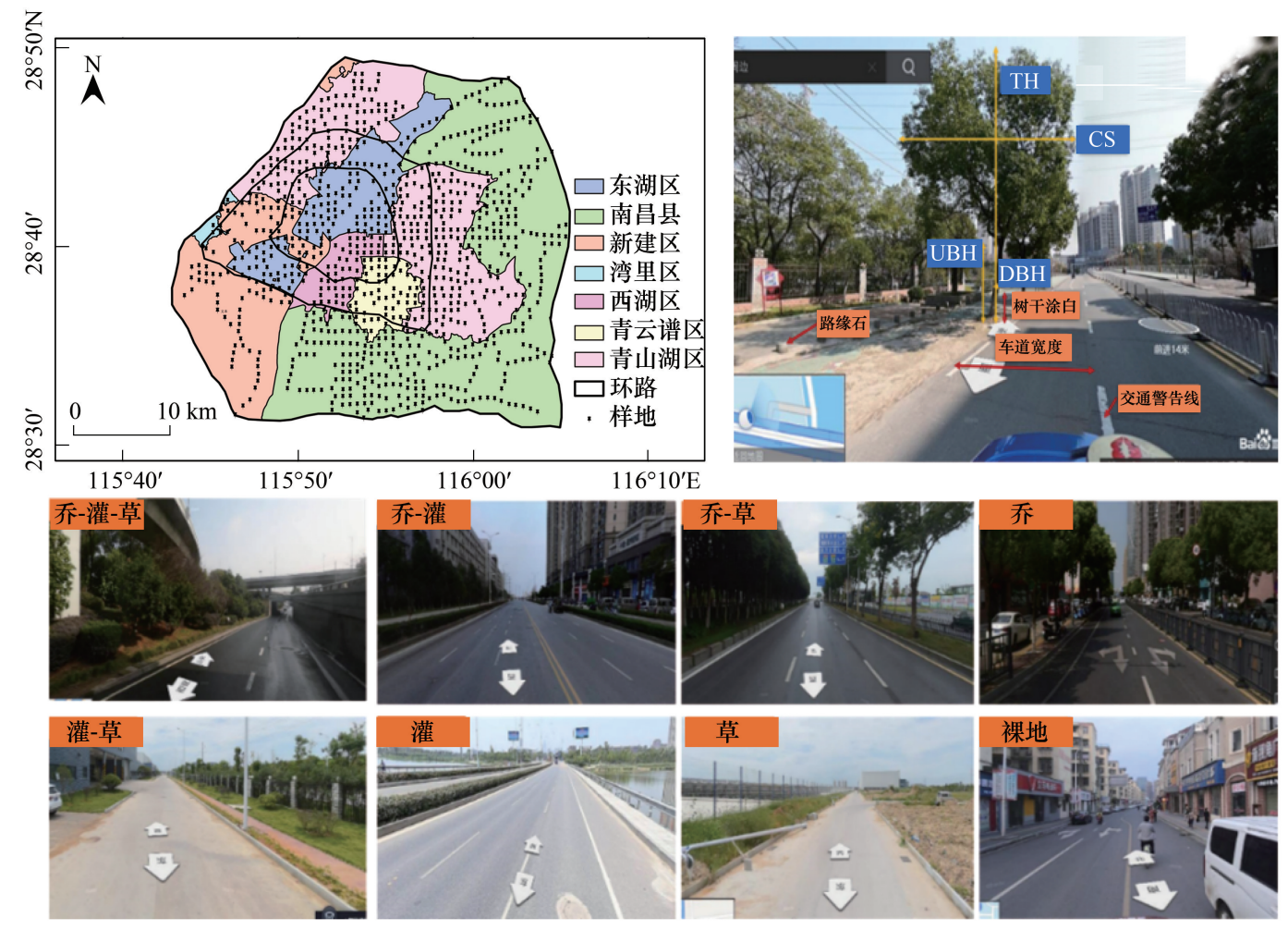

图 1 调查样地在南昌市的空间分布、研究测量方法图示和垂直结构类型

Fig.1 The spatial distribution of the sample plot in Nanchang, the measurement method and the vertical structure types in this study DBH: 胸径 diameter at breast height;UBH:冠下高 underbranch height;TH:树高 tree height; CS: 冠幅 canopy size

1.2 基于街景照片行道树数据的获取

在百度街景地图中对南昌市进行网格化布点,网格大小为 $600 \mathrm{~m}$, 全市共设置 963 个样点( 图 1)。全景模 式下进人每个样点的网络街景地图, 识别 $100 \mathrm{~m}$ 道路样地行道树信息 (作为一个样地), 当百米内遇到围墙、 栅栏等时, 以遮挡物为止所有树木所在样地进行统计, 研究区域内共调查 26727 株行道树。不同指标的测量 方法具体包括:

树木大小测量 (图 1): 参照城市行道树街景测树法 ${ }^{[8]}$, 采集并下载街景照片, 导人 ImageJ 软件测量各指 标。选择固定的参考标准, 如路缘石的高度 15-20 cm (平均值 $18 \mathrm{~cm}$ : CJJ37-2012 城市道路工程设计规范标 准)、交通警告标线宽 $15 \mathrm{~cm}$ ( 国标名称: GB5768-1999)、行道树涂白漆高度 (1.0-1.3 $\mathrm{m}$ : 经验值) 和车道宽度 (3.5 m: 道路交通标志和标线国家标准) 等。测量样地内所有树木的各指标,平均值表示该样地的树木的胸 径、树高、冠下高和冠幅。

树木健康状况采用视觉评价法。评价方法: 1) 支架比例: 样地内支架支撑的树木占树木总数的百分比 (帮助树木生存);2) 枯梢比例: 样地内有枯梢的树占树木总数的百分比;3) 叶色不健康比例: 样地内叶色异常 树占树木总数的百分比; $)$ 死亡比例: 样地死树占树木总数的百分比。4 个参数用于评价树木健康状况, 参数 百分比越高, 健康状况越差。就叶片颜色而言, 大多数植物健康色为绿色, 非绿色为不健康状态, 对于某些特 殊种 (如紫叶李等), 则以颜色较深的为健康, 明显变色的定义为不健康。我们选择在植物生长季街景图完成 调查,所有工作在 2017 年夏季完成。 
垂直结构采用视觉评价法。记录方法为: 目测识别样地内行道树及其附属植被的结构类型 (图 1), 规定 结构类型的确定规则: $100 \mathrm{~m}$ 范围内两侧道路非硬质路面上, 即有土壤地面上, 各植被类型绿化土地面积占比 情况确定其垂直结构等级,具体分类如下:

1) 有乔木,灌木绿化率达 $20 \%$ 以上, 草本达 $20 \%$ 以上,为乔灌草 (7);

2) 有乔木, 灌木绿化率达 20\%以上,无草本或低于 $20 \%$,为乔灌 (6);

3 ) 有乔木, 无灌木或低于 $20 \%$, 草本达 $20 \%$ 以上, 为乔草 (5);

4) 有乔木, 无灌木或低于 $20 \%$,无草本或低于 $20 \%$,为乔 (4);

5) 无乔木, 灌木绿化率达 20\%以上, 草本达 20\%以上, 为灌草 (3);

6) 无乔木, 灌木绿化率达 20\%以上,无草本或草本低于 $20 \%$,为灌 (2);

7 ) 无乔木, 无灌木或低于 $20 \%$,草本高于 $20 \%$,为草 (1);

8 ) 硬质面、土壤无植被、无乔木且灌木和草本均低于 $20 \%$ 均为裸地 $(0)$ 。括号内数字从 0 到 7 代表垂直 结构等级复杂程度,所有信息记录到 Excel 中。社会发展情况也进行观察记录。具体包括 $100 \mathrm{~m}$ 内行人数、 行驶车辆数、路边停车数、路边商铺数量、道路车道数、道路绿化带宽度, 用于分析社会发展情况, 以便后续相 关性分析。

\section{3 数据分析}

使用 JMP10.0 软件对行道树大小指标、健康状况和垂直结构进行统计分析，绘制频率分布箱线图，图内包 括的指标包括平均值 (菱形)、中位数 (长方形中线)、上四分位数 (长方形上缘)、下四分位数 (长方形下缘) 和 异常值(黑点); 红线表示 $50 \%$ 数据最小集中区域。

就林分健康而言,样地内树木支架比例、枯梢比例、叶色不健康比例、死亡比例越接近 $0 \%$, 则该林分整体 健康越良好。为方便分析, 上述指标 $<1 / 4$ 的样地定义为林分健康良好, 在 $1 / 4$ 到 $1 / 2$ 的样地定义林分健康状 况一般, 而占比 $>1 / 2$ 时定义为林分健康较差。

通过 ArcGIS10.2 克里金插值模块确定各指标空间分布情况。单因素方差与多重分析比较用于分析不同 行政区和不同环路的树木大小、健康状况、垂直结构等级差异, 统计在 SPSS22.0 中完成。在 Canoco5.0 中运用 圥余分析用于确定树木大小、垂直结构、健康状况与社会因子和道路因子间的复杂关系, 为行道树管理提供 参考。

\section{2 结果}

2.1 行道树大小频率与空间分布

南昌市行道树平均胸径 $16.66 \mathrm{~cm}$, 平均冠下高 $2.04 \mathrm{~m}$, 平均树高 $6.17 \mathrm{~m}$, 平均冠幅 $4.65 \mathrm{~m}$ 。行道树大小分 布相对集中, 如图 2 所示, 树胸径主要集中在 10-20 cm, 冠下高主要集中在 1-2.5 m, 占比 $76 \%$; 树高度集中 在 4-8 m, 占比 71\%; 冠幅主要集中在 2-6 m, 占比 76\%。

南昌市行道树大小在不同行政区间存在差异。综合分析来看, 小树在南昌县、新建区、湾里区大面积分 布, 大树主要分布在东湖区、西湖区。且在不同环路间则显示出大树主要分布在靠近内环区域、较小的树主要 分布在城市外围的空间分布规律 ( 图 3)。

2.2 行道树健康频率与空间分布

南昌市行道树多数健康状况良好。调查样地中不健康状况处于较低的水平,频率分布如图 4 显示, $77 \%$ 的样地中行道树没有支架, $69 \%$ 的样地中行道树没有枯梢, $35 \%$ 的样地行道树叶片颜色健康, $93 \%$ 的样地无 死树。

行道树健康状况空间分布显示行道树管理的潜在危险区域(图 5)。综合各指标分析,青山湖、新建区、青 山湖区存在林分健康等级较差的区域,湾里区局部地区、青山湖区大部分区域林分健康等级为一般,其他区域 林分健康等级为良好。其中, 空间分布清楚地显示了整个城市西部区域行道树叶片健康较东部区域差。 

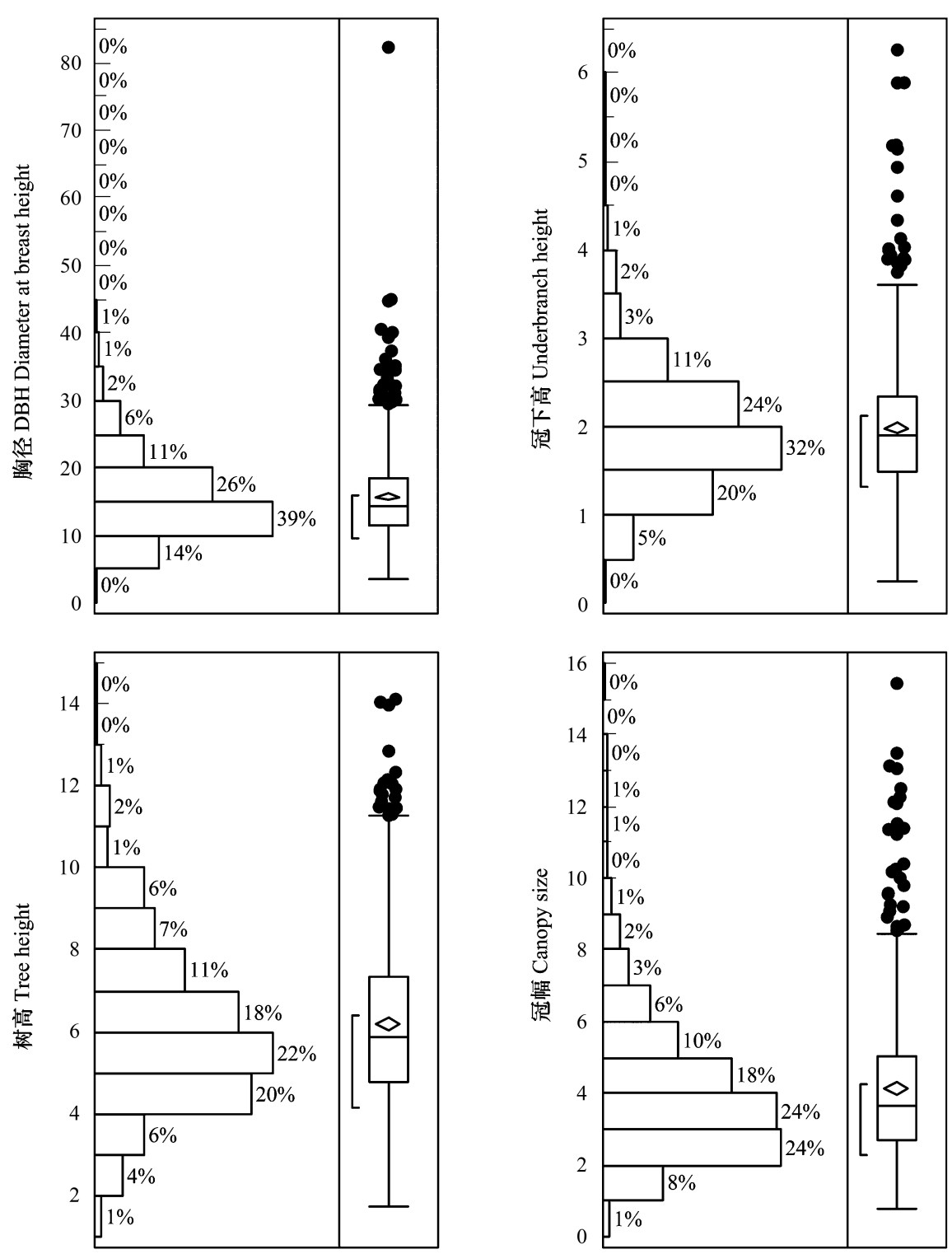

图 2 南昌市行道大小指标分布箱线图

Fig.2 Box-plots of tree size factors of roadside trees in Nanchang

\section{3 植被垂直结构频率分布与空间分布}

南昌市垂直结构等级配置情况整体较好。如图 6 所示,植被垂直结构以乔-灌-草结构为主, 占比为 75\%, 而裸地占比为 $3 \%$; 空间分布图则显示, 东湖区、西湖区出现大面积等级较低、结构简单的植被类型,其他地区 结构等级较高, 以多层为主; 且不同环路间表现出内环多为结构等级较低、外环则多为等级较高的空间分布 格局。

2.4 不同行政区间行道树大小、健康状况及垂直结构差异分析

南昌市不同行政区行道树胸径、冠下高、树高及冠幅均有显著差异 $(P<0.05)$ 。单因素方差分析与多重比 较结果显示, 东湖区各行道树各指标显著高于其他区域, 如冠幅平均高出 $1.5-3 \mathrm{~m}$, 树高平均高出 $1.2-$ $1.7 \mathrm{~m}$, 而新建区行道树则相对较小 (表 1 )。

南昌市不同行政区行道树支架比例、叶片不健康比例差异显著 $(P<0.05)$ 。新建区支架比例显著高于东 湖区、湾里区; 新建区和湾里区叶色不健康状况比例显著高于西湖区、青云谱区; 不同行政区间行道垂直结构 


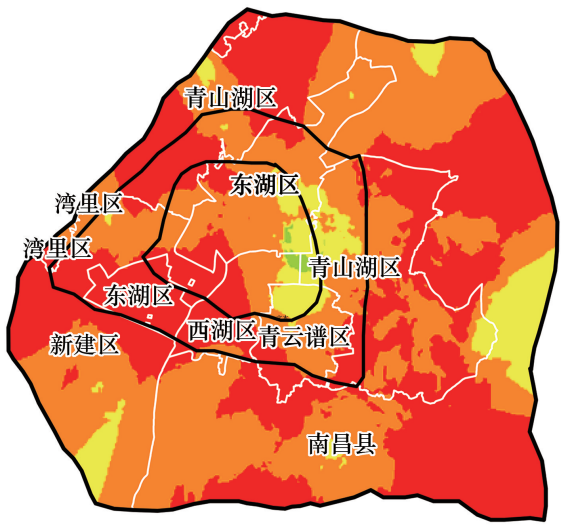

胸径 $/ \mathrm{cm}$
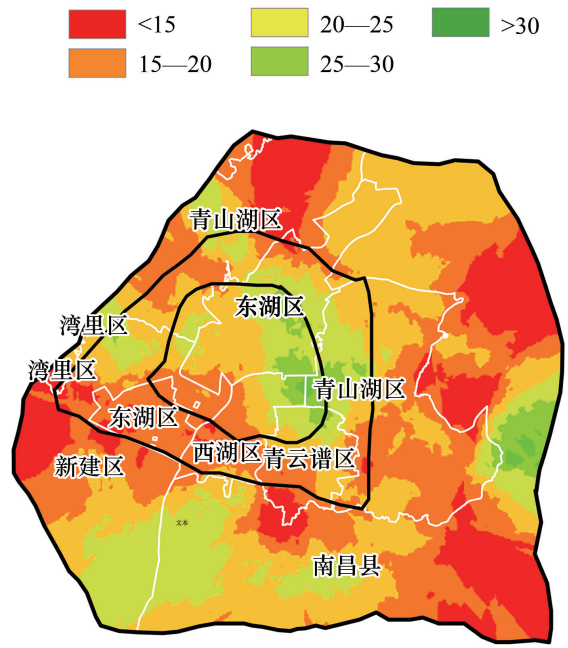

树高 $/ \mathrm{m}$

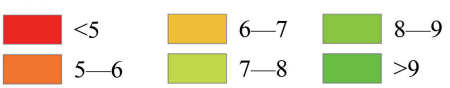

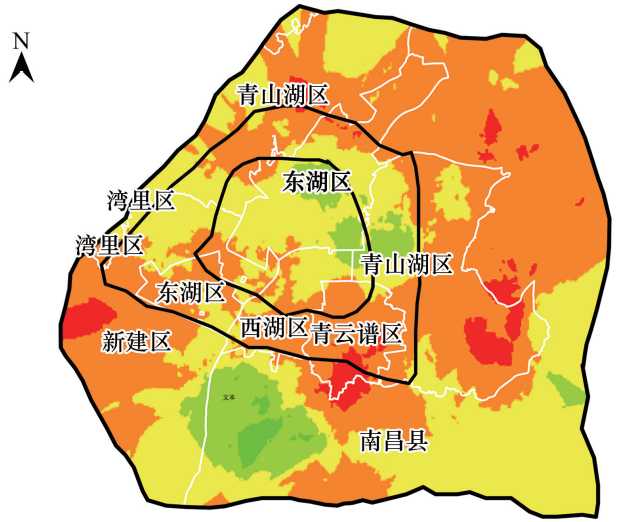

冠下高 $/ \mathrm{m}$
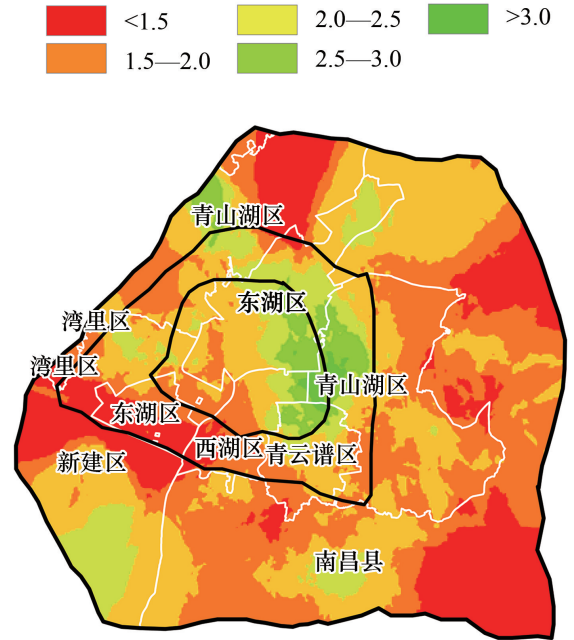

冠幅/m

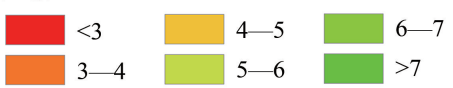

$10 \mathrm{~km}$

图 3 南昌市行道树大小空间分布图

Fig.3 Spatial distribution map of street tree sizes in Nanchang

表 1 南昌市不同行政区间树木生长状况比较

Table 1 Differences of trees size among administrative region in Nanchang

\begin{tabular}{|c|c|c|c|c|c|c|c|}
\hline 因子 Parameters & 西湖区 & 青云谱区 & 青山湖区 & 南昌县 & 东湖区 & 新建区 & 湾里区 \\
\hline \multicolumn{8}{|l|}{ 树木大小 Trees size } \\
\hline 树高 $\mathrm{TH} / \mathrm{m}$ & $6.46 \mathrm{ab}$ & $6.42 \mathrm{ab}$ & $6.31 \mathrm{~b}$ & $5.88 \mathrm{~b}$ & $7.57 \mathrm{a}$ & $5.81 \mathrm{~b}$ & $5.62 \mathrm{~b}$ \\
\hline 冠下高 UBH/m & $2.08 \mathrm{~b}$ & $1.84 \mathrm{~b}$ & $2.03 \mathrm{~b}$ & $2.02 \mathrm{~b}$ & $2.46 \mathrm{a}$ & $2.02 \mathrm{~b}$ & $1.93 \mathrm{~b}$ \\
\hline 冠幅 CS/m & $4.66 \mathrm{bc}$ & $5.41 \mathrm{~b}$ & $4.87 \mathrm{bc}$ & $4.12 \mathrm{bc}$ & $6.91 \mathrm{a}$ & $4.26 \mathrm{bc}$ & $3.90 \mathrm{c}$ \\
\hline 胸径 $\mathrm{DBH} / \mathrm{cm}$ & $16.59 \mathrm{~b}$ & $18.49 \mathrm{~b}$ & $16.73 b$ & $15.94 b$ & $22.40 \mathrm{a}$ & $15.38 b$ & $17.14 b$ \\
\hline \multicolumn{8}{|l|}{ 健康与结构 Health and structure } \\
\hline 支架比例 Tripod-supporting/\% & $10.69 \mathrm{ab}$ & $5.08 \mathrm{ab}$ & $6.88 \mathrm{ab}$ & $13.51 \mathrm{ab}$ & $2.28 \mathrm{~b}$ & $18.15 \mathrm{a}$ & $0.4 \mathrm{~b}$ \\
\hline 叶色不健康比例 Non-green leaf/\% & $55.37 \mathrm{~b}$ & $24.03 \mathrm{c}$ & $43.89 \mathrm{bc}$ & $45.92 \mathrm{bc}$ & $27.05 \mathrm{c}$ & $77.10 \mathrm{a}$ & $78.29 \mathrm{a}$ \\
\hline 枯稍比例 Die-back/\% & $8.33 \mathrm{a}$ & $8.83 \mathrm{a}$ & $9.70 \mathrm{a}$ & $7.36 \mathrm{a}$ & $6.95 \mathrm{a}$ & $21.14 \mathrm{a}$ & $14.49 \mathrm{a}$ \\
\hline 死亡比例 Death/\% & $0.31 \mathrm{a}$ & $1.50 \mathrm{a}$ & $0.98 \mathrm{a}$ & $0.39 \mathrm{a}$ & $0.42 \mathrm{a}$ & $1.06 \mathrm{a}$ & $1.07 \mathrm{a}$ \\
\hline 结构得分 Structure score & $5.04 \mathrm{~b}$ & $5.97 \mathrm{ab}$ & $6.26 \mathrm{a}$ & $5.96 \mathrm{ab}$ & $5.28 \mathrm{ab}$ & $6.22 \mathrm{a}$ & $6.00 \mathrm{ab}$ \\
\hline
\end{tabular}

不同字母表示差异显著 $(P<0.05)$; DBH: 胸径 diameter at breast height; UBH: 冠下高 underbranch height; TH: 树高 tree height; CS: 冠幅 canopy size 

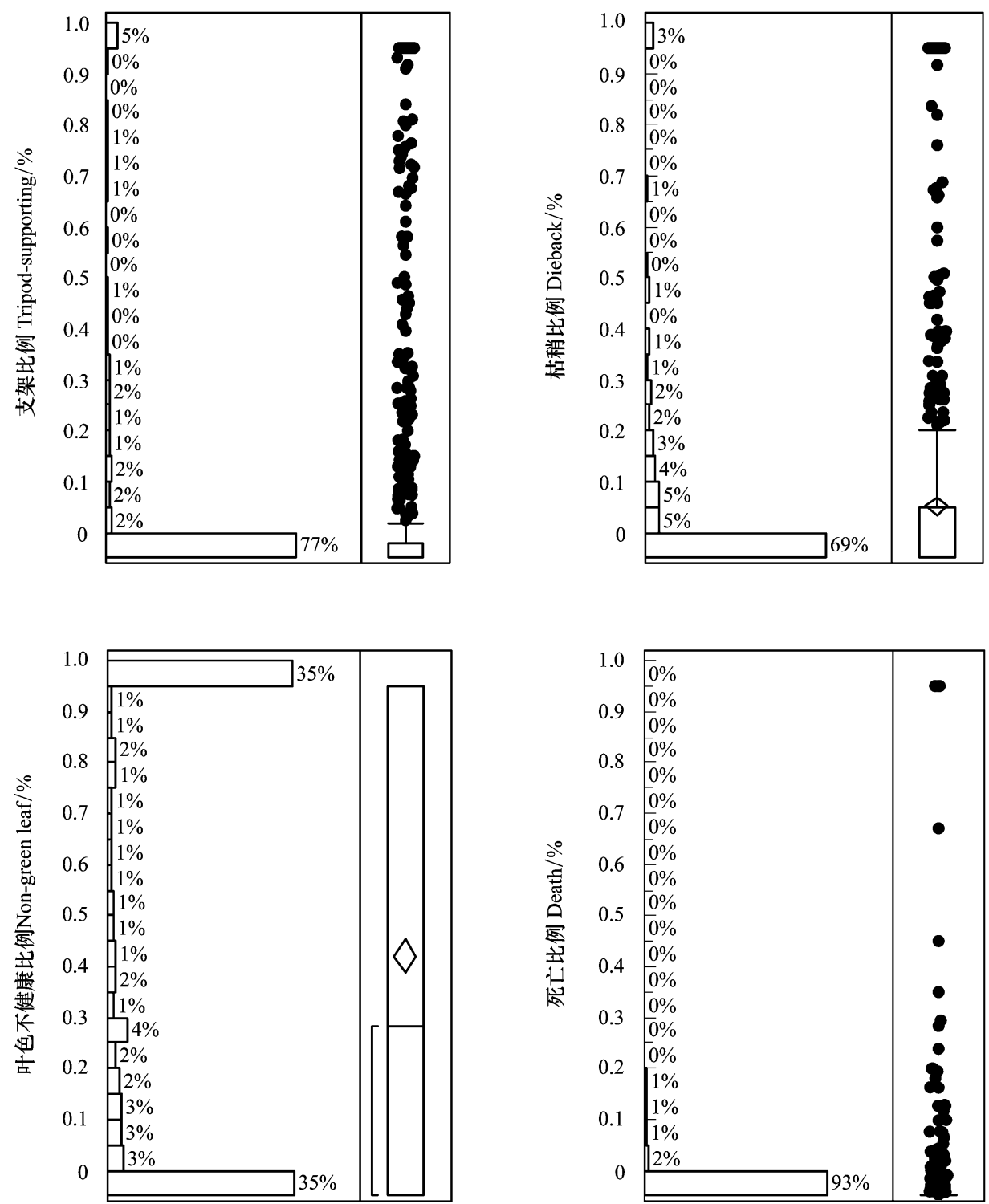

图 4 南昌市行道树木健康指标分布箱线图

Fig.4 Box-plots of health index distribution of roadside trees in Nanchang

配置等级差异显著 $(P<0.05)$ 。青山湖区、新建区结构配置等级显著高于西湖区, 青山湖区配置等级最高, 西 湖区等级最低 (表 1 )。

2.5 不同环路间行道树大小、健康、立体结构差异分析

南昌市行道树不同环路间树高、冠下高、胸径、冠幅差异显著 $(P<0.05)$ 。各指标大小在环路上均表现出 1 环>2 环>3 环空间分布规律。不同环路间行道树叶色不正常比例差异显著 $(P<0.05)$ 。叶色不健康状况比例 2 环最高, 显著高于 3 环, 其他指标在不同环路间差异没有达到显著水平。不同环路间垂直结构配置情况差 异显著 $(P<0.05)$ 。3 环结构得分最高, 1 环最低,垂直结构配置等级从外环到内环呈降低趋势 (表 2)。

2.6 行道树大小、健康状况与社会发展因子耦合关系分析

社会发展因子与行道树结构特征和健康状况关系较大。从第一轴分析, 社会发展因子 (商铺量、静态车 流量、人流量) 与行道树大小指标多呈正相关关系, 但是与健康状况、植被垂直结构等级多呈负相关关系, 而 道路因子 (车道数) 与行道树大小多呈负相关关系, 与健康状况、植被垂直结构呈正相关关系。从第二轴分 

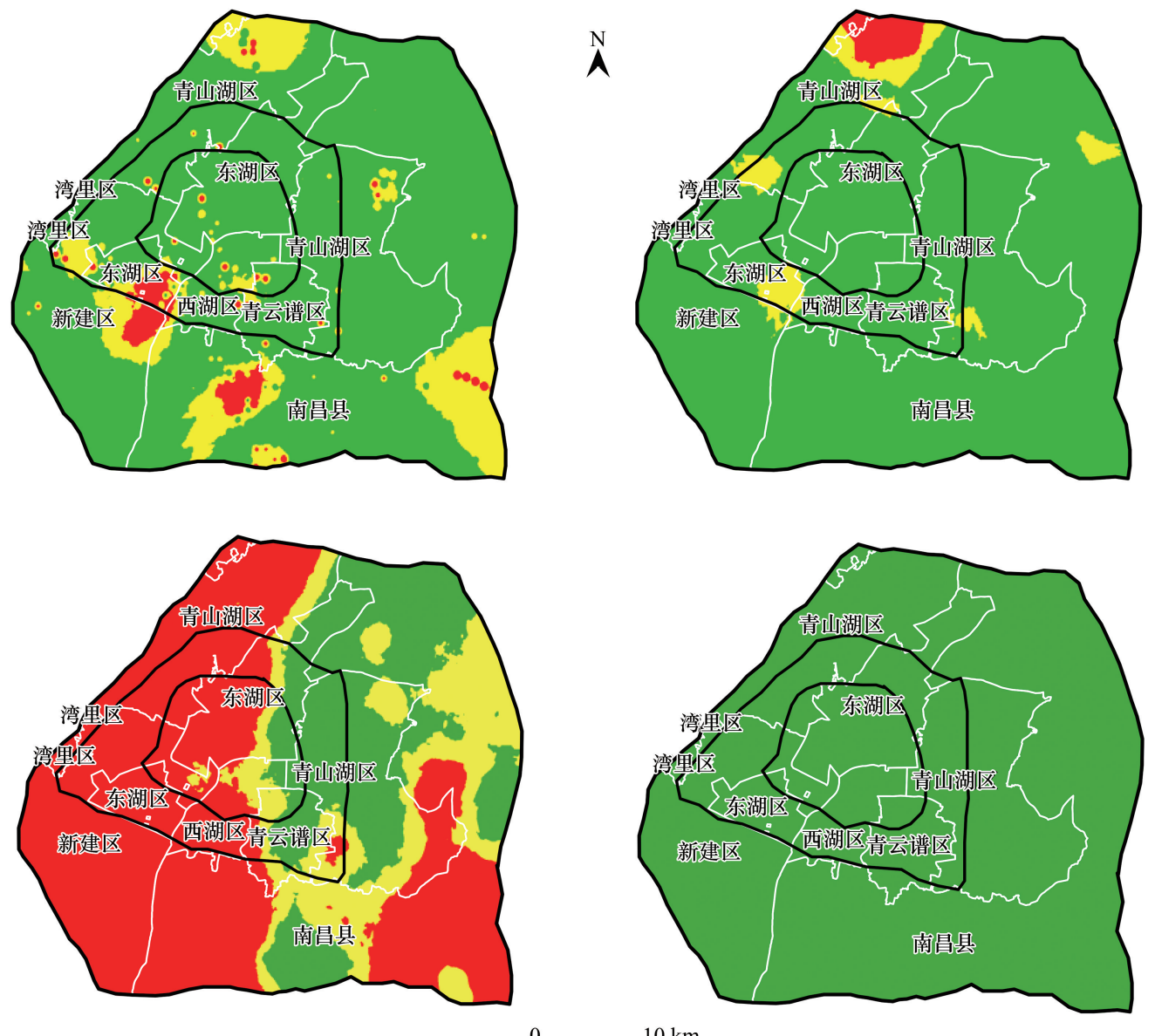

$10 \mathrm{~km}$

健康等级

良好 $<25 \%$

一般 $25 \%-50 \%$

较差 $>50 \%$

图 5 南昌市行道树健康状况空间分布

Fig.5 Spatial distribution map of health status of roadside trees in Nanchang
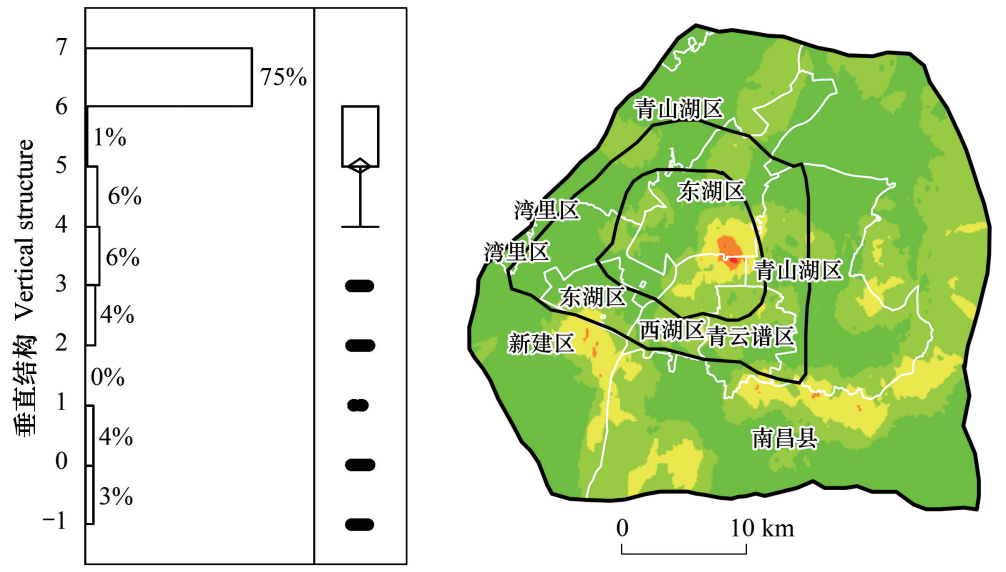

A

重直结构

3 灌-草

4 乔

$5 \square$ 乔-草

6 乔-灌

7 乔-灌-草

图 6 南昌市行道树各结构等级占比情况及空间分布

Fig.6 The proportion of each vertical structural grade in Nanchang Roadside trees and its spatial distribution 
析, 动态车流量、道路绿化宽度、行道树密度与健康状况呈负相关关系。总而言之,较高水平的社会发展因子 会导致较大个体出现, 但是较低水平的道路因子 (窄绿化宽度、窄道路和低树木密度) 会伴随着简单的垂直结 构和较好的个体健康( 图 7)。

表 2 南昌市不同环路间树木生长状况差异分析

Table 2 Analysis on the difference of tree growth among different ring roads in Nanchang

\begin{tabular}{lccc}
\hline 因子 Parameters & 1 环 $1^{\text {st }}$ ring road & 2 环 $2^{\text {nd }}$ ring road & 3 环 $3^{\text {rd }}$ ring road \\
\hline 树木大小 Trees size & & & $5.15 \mathrm{~b}$ \\
树高 TH/m & $7.09 \mathrm{a}$ & $2.02 \mathrm{~b}$ & $1.99 \mathrm{~b}$ \\
冠下高 UBH/m & $2.26 \mathrm{a}$ & $4.19 \mathrm{c}$ \\
冠幅 CS/m & $5.89 \mathrm{a}$ & $4.83 \mathrm{~b}$ & $16.00 \mathrm{~b}$ \\
胸径 DBH/cm & $19.14 \mathrm{a}$ & $16.65 \mathrm{~b}$ & \\
健康与结构 Health and structure & & & $11.93 \mathrm{a}$ \\
支架比例 Tripod-supporting/\% & $8.79 \mathrm{a}$ & $9.81 \mathrm{a}$ & $45.55 \mathrm{~b}$ \\
叶色不健康比例 Non-green leaf/\% & $49.16 \mathrm{ab}$ & $55.17 \mathrm{a}$ & $8.71 \mathrm{a}$ \\
枯稍比例 Dieback/\% & $7.06 \mathrm{a}$ & $15.16 \mathrm{a}$ & $3.12 \mathrm{a}$ \\
死亡比例 Death/\% & $1.14 \mathrm{a}$ & $1.10 \mathrm{a}$ & $6.33 \mathrm{a}$ \\
结构得分Structure score & $5.43 \mathrm{c}$ & $5.97 \mathrm{~b}$ & \\
\hline
\end{tabular}

RDA 轴从原始数据中提取了 $92.89 \%$ 的信息,各因子总共解释力为 $13 \%$ 。各因子的单独解释量如表 3 所 示, 行道树密度、车道数解释力最大, 且各因子的解释均达到了极显著的水平 $(P<0.01)$ 。当去除共线性影响 之后, 只有绿化带宽度为解释力未达到显著性。

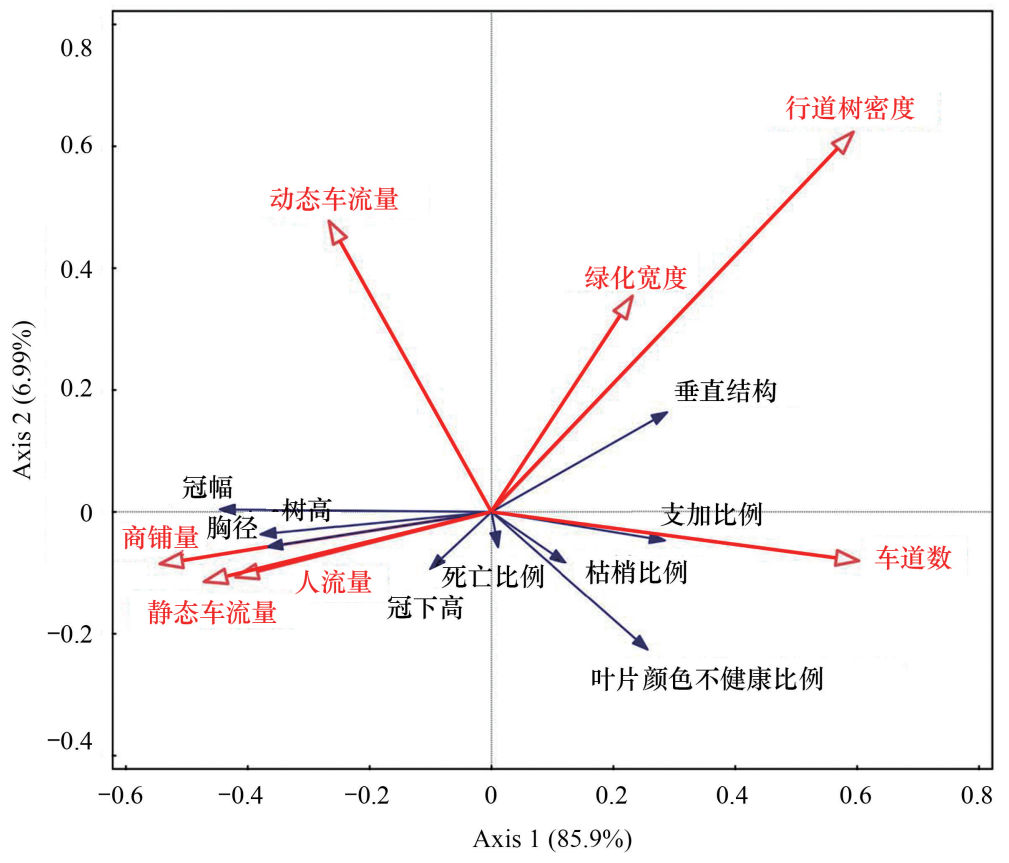

图 7 南昌市行道树大小、健康状况和垂直结构与社会发展因子、道路因子耦合关系的几余分析

Fig.7 RDA analysis of the coupling associations between the tree size, health status, vertical structure and social development factor and road factor in Nanchang

RDA, 圥余分析 redundancy analysis

\section{3 讨论}

3.1 基于街景测量城市森林的优势及需要注意的事项

在线街景地图能够有效提高街道因子数据集的更新速度 ${ }^{[18]}$, 被广泛应用于城市生态及街道因子调 
查 ${ }^{[19]}$ 。针对南昌市的树木调查进一步证实了我们前期的研究结论 ${ }^{[8]}$ : 街景技术可用于测量行道树的大小, 同 时也证明了其在视觉评价林分健康与垂直结构的有效性。其优点是效率高、速度快, 可以替代大规模的野外 调查。野外实测工作中, 对哈尔滨 ${ }^{[20]}$ 、长春市 ${ }^{[21]}$ 区内主要街道行道树结构特征和健康状况调查, 每个城市耗 时 2-3 个月且多人合作完成。本研究 1 人用 3 周时间完成了 963 块采样地的 26727 棵道路树木的测量,测 量参数与较上述文献相近甚至更多, 测量样地数更多。在测量精度上, 胸径、树高 (树高和冠下高) 和冠幅的 精度最高分别为 $92 \% 、 87 \%$ 和 $80 \%$,其所需的人力和时间是实地调查所需的 $10 \%$ 左右 ${ }^{[8]}$ 。

表 3 基于 RDA 分析的不同条件下各因子对行道树大小、健康、垂直结构的解释量及其显著性

Table 3 The explanatory quantities and significance of each factor to the size, health and vertical structure of the street tree under different conditions based on RDA analysis

\begin{tabular}{lccc}
\hline 独立效应 Simple explains & & & \\
\hline 因子 Parameters & 解释量 Explains/\% & $P$ \\
\hline 行道树密度 Road tree density & 4.4 & 30.2 & 0.002 \\
车道数 Number of lanes & 3.4 & 29.8 & 0.002 \\
商铺量 Amount of shops & 3.6 & 24.2 & 0.002 \\
静态车流量 Static traffic flow & 2.6 & 17.5 & 0.002 \\
人流量 Number of pedestrians & 2 & 13.4 & 0.002 \\
动态车流量 Dynamic traffic flow & 1 & 6.7 & 0.004 \\
绿化带宽度 Green belt width & 0.8 & 5.3 & 0.01 \\
\hline 条件效应 Conditional explains & & & 0.002 \\
\hline 行道树密度 Road tree density & 4.4 & 30.2 & 0.002 \\
车道数 Number of lanes & 3.1 & 22.3 & 0.002 \\
商铺量 Amount of shops & 2.7 & 18.5 & 0.002 \\
动态车流量 Dynamic traffic flow & 1.7 & 12.4 & 0.01 \\
静态车流量 Static traffic flow & 0.7 & 5.3 & 0.0296 \\
人流量 Number of pedestrians & 0.2 & 1.2 & 0.324 \\
绿化带宽度 Green belt width & 0.2 & 1.1 & \\
\hline
\end{tabular}

林分健康视觉评价尚缺乏固定的标准,特别是街景像素过低的限制。比如: 1) 在叶片颜色正常与否的观 察上,除了传统的绿色、非绿色界定为健康与否外,还需要考虑某些彩叶树种, 如紫叶李、红叶石楠 ${ }^{[13,22]}$, 其颜 色往往越深越健康。这就需要测量人对主要行道树树种有分辨能力; 考虑到行道树种类仅 5-6 类和分类树 种主要数十种 ${ }^{[13,22]}$, 提前熟悉相关树种照片具有可行性。南昌市樟树、秃瓣杜英等 10 种树种出现频率 $81.10 \%$,其中樟树的出现频率为 $61.21 \%^{[13]}$; 我们通过街景 ${ }^{[23]}$ 也确认南昌市主要树种为樟树、悬铃木、奕树 等,但无法识别的树种达到 $21.3 \%$ 。2) 利用支架表征行道树健康度,主要考虑的是新栽植树木往往并未扎实 根系; 如果某一区域内新移植树木较多, 其生态服务功能发挥将受影响。3) 更多的指标可能用于健康评价, 尚需建立适宜标准。比如不同行道树树种的树木生长状态并不相同, 树木分叉点、枝下高、冠幅等修剪保留不 尽一致, 在枯梢量占比、死亡比例评价上容易造成较大误差。未来在街景调查中充分考虑不同树种, 将有利于 提出更加切实可行的、在造林学种水平上的林分管理建议。落叶树木的修剪期一般为自晚秋至早春, 减少视 觉检查的偏差,我们选择在夏季的街景照片进行调查。另外,许多行道树的健康状况还受到了生存空间被挤 占、水肥管理措施不当等多方面因素的影响,这些因素本研究也未考虑。整体来看, 与野外视觉评价一样, 街 景视觉检查树木健康可能存在系统性误差, 未来考虑多人共同评价、增加可行性指标来减少误差。

街景测树方面需要综合考虑标尺问题, 以提升测定指标的精度。本团队对街景测树法精确度也进行了相 关的研究 ${ }^{[8]}$, 结果发现街景中常见参照物可用于树木大小的远程估计, 并对不同参照标准如树木涂白、路缘 石等高度下的树木测量精度, 其中涂白被证明是最精确的参照 $\left(R^{2}=0.82-0.97\right)$, 而综合标尺的精度最高; ImageJ 软件是较好的综合各参照物标准的测量软件, 能够大大提高测量精度; 对参照物的准确标注、周围环境 
(与其他树的距离)、测量角度和采集位置 (光线问题)均会影响测量精度。在实测中,采用综合标尺(就近选 择固定大小的物体作为标尺)参照物, 采集照片与标尺尽量在一个平面内、选择表征树整体合适角度和位置, 并进行前期练习培训是进行街景测量的必要过程。

\section{2 南昌城市森林的空间分布: 以往研究的更新}

分析城市树木大小和健康状况的分布规律, 并与以往研究进行对比, 是开展城市树木管理的前提。本研 究的主要发现包括 2 点。

第一, 通过街景测树法对南昌市行道树结构和林分健康的远程调查是对以往研究的更新。以往针对南昌 市行道树的大量研究显示出城市森林的重要生态功能。如: 尤春波等人对南昌市主要街道行道树调查统计显 示中径阶树为 $69 \%$, 且健康总体达到了中等水平 ${ }^{[13]}$; 与此不同, 周宇婷等人也对市内小面积区域研究发现没 有优质等级的行道树个体 ${ }^{[22]}$ 。这些研究局限于某一小范围或受野外实测的限制, 不能对整个市区进行有效 性评价和实时更新。本研究利用街景技术较为系统、全面的对南昌市整体行道树特征进行评价,即南昌市行 道树整体较小, 南昌县和新建区小树居多; 湾里区、新建区林分健康情况较差;西湖区、东湖区的植被垂直结构 等级配置较差。这些结果将为南昌市的城市行道树精细化管理提供新参考。

第二,城市化影响具有规律性,在构建良好城市环境中需要考虑这一点。提前新区造林方案进行设计、加 强现有林管理,使得城市森林成为低投人、高产出、长效的绿色基础设施。本研究和前期研究都发现城市化对 森林相关属性的规律性影响。大量研究城市化会影响大小和健康 ${ }^{[24]}$ 、相关景观指数 ${ }^{[25-26]}$ 、物种丰富度 ${ }^{[27]}$ 等 的空间分布趋势。本研究发现, 南昌市行道树在城乡梯度上表现出行道树单个个体减小, 垂直结构逐渐复杂 化。这可能与城市化程度越高、人为干扰越强、树木生长可能受到越强的限制 ${ }^{[27]}$ 有关。在未来城市化影响评 价以及森林城市、花园城市和生态城市建设中应该充分考虑这种城市化的长期影响。

\section{3 南昌市绿色基础设施: 问题与建议}

南昌市是江西省最重要的城市,在未来城市绿化过程中,需要关注如下几点。首先,空间图示显示出不同 区域行道树大小的显著差异,比如:行道树幼树主要集中在南昌县和新建区, 大树主要分布在东湖区和西湖 区, 这些信息以往研究中报道很少 ${ }^{[28]}$ 。大树可以提供更好的生态服务,很多研究强调其保护 ${ }^{[29-32]}$, 本研究指 出了其存在区域。为提高城市行道树服务功能, 强调在幼树较多的区域应当注意其生长管理, 而树龄较大的 老树需注重养护。同时,本研究的调查地点的经纬信息能够定位行道树区域,为城市管理者提供数据基础。

其次,南昌市行道树整体上健康状况良好,但是局部地区依然存在问题。青山湖区、新建区林分健康较 差, 西部区域行道树叶片颜色不正常比例普遍较高。叶片异常的观察可能存在不足 ${ }^{[13,22]}$, 但是至少证明了南 昌市行道树叶片健康在空间格局上存在差异。行道树管理和维护上,应当在支架比例较高的林分区域,加强 维护和管理, 使其自理能力增强。及时修剪枯梢, 及时补充营养, 清除死树并有计划的进行植树, 有效提高生 态服务功能。

最后,南昌市植被垂直结构空间分布呈现规律性。外环等级最高, 内环最差,应当在市中心种植不同类型 植被、裸地种植植被,避免商业区开发导致绿化减少。而针对如西湖区结构等级较差的问题,城市管理者在规 划路边树木时, 应以人类活动频繁的地点为重点, 种植抗逆性强的树种, 注重不同植被类型的结合以提高多样 性和生态稳定性。

\section{4 结论}

南昌市行道树整体小树较多,健康状况整体良好,植被垂直结构较优, 且在空间上呈现显著的城乡梯度变 化规律, 即从内环到外环, 行道树个体变小,垂直结构逐渐复杂化。城市森林空间分布图的完善为南昌市城市 森林精准管理提供了基础。本研究采用的快速、准确的街景网络测树的调查方法, 为今后的全国大尺度调查 奠定了基础。 


\section{参考文献 (References)：}

[ 1 ] Wang W J, Zhang B, Xiao L, Zhou W, Wang H M, He X Y. Decoupling forest characteristics and background conditions to explain urban-rural variations of multiple microclimate regulation from urban trees. PeerJ, 2018, 6: e5450.

[ 2 ] McPherson E G, Van Doorn N, De Goede J. Structure, function and value of street trees in California, USA. Urban Forestry \& Urban Greening, 2016, 17 : 104-115.

[ 3 ] 刘华斌, 杨梅, 李宝勇, 过仕云, 古新仁. 基于生态安全的城市绿色廊道系统规划研究一一以南昌市为例. 中国园林, 2020, 36(4)： 122- 127.

[ 4 ] Richards D R, Edwards P J. Quantifying street tree regulating ecosystem services using Google Street View. Ecological Indicators, 2017, 77: $31-40$.

[ 5 ] 郑屹, 杨俊宴. 基于大规模街景图片人工智能分析的精细化城市修补方法研究. 中国园林, 2020,36(8): 73-77.

[ 6 ] Meunpong P, Buathong S, Kaewgrajang T. Google Street View virtual survey and in-person field surveys: an exploratory comparison of urban tree risk assessment. Arboricultural Journal, 2019, 41(4) : 226-236.

[ 7 ] Liang J M, Gong J H, Zhang J M, Li Y, Wu D, Zhang G Y. GSV2SVF-an interactive GIS tool for sky, tree and building view factor estimation from street view photographs. Building and Environment, 2020, 168: 106475.

[ 8 ] Wang W J, Xiao L, Zhang J H, Yang Y, Tian P L, Wang H M, He X Y. Potential of Internet street-view images for measuring tree sizes in roadside forests. Urban Forestry \& Urban Greening, 2018, 35: 211-220.

[ 9 ] Li X J, Ratti C, Seiferling I. Quantifying the shade provision of street trees in urban landscape: a case study in Boston, USA, using Google Street View. Landscape and Urban Planning, 2018, 169: 81-91.

[10］韩旭，黄晓园，马兴永. 基于 GIS 技术的南昌市城市森林景观特征分析. 林业调查规划, 2019，44(5): 22-25.

［11］杨玉涵，杨馥宁，杨家林，赖国祯. 南昌市森林资源保护现状及对策. 林业建设, 2018，(3) : 35-39.

[12］万承永，何叶，曹继荣. 发展森林资源对改善南昌城市环境的探析. 林业建设, 2018，(3) : 48-51.

[13] 尤春波. 南昌市城市森林建设中道路主要绿化树种选择及其应用研究 [D]. 长沙: 中南林业科技大学, 2013.

[14] 王亚平. 城市道路绿化一一南昌红谷滩绿地国博城旁道路绿化为例. 现代园艺, 2017，(8) : 175-176.

[15] 王珍珍. 南昌市道路绿地的植物配置及滞尘效应 [D ]. 南昌: 东华理工大学, 2019.

[16] 杨惁杰. 南昌市环境水利问题. 江西水利科技, 1985, (3) : 20-31.

[17］胡小飞, 傅春. 南昌城市绿地系统生态调节服务功能价值动态分析. 江西农业大学学报, 2014, 36(1) : 230-237.

[18] Alcantarilla P F, Stent S, Ros G, Arroyo R, Gherardi R. Street-view change detection with deconvolutional networks. Autonomous Robots 2018,42 (7) : 1301-1322.

[19] Li X J, Zhang C R, Li W D, Ricard R, Meng Q Y, Zhang W X. Assessing street-level urban greenery using Google Street View and a modified green view index. Urban Forestry \& Urban Greening, 2015, 14(3): 675-685.

[20] 张波, 王文杰, 周伟, 肖路, 吕海亮, 魏晨辉. 哈尔滨城市森林树木生长状况及各生长指标的相关性分析. 安徽农业科学, 2016, 44 (26) : 127-128, 154- 154 .

[21] 李娟,韩姣,王晓娜,李青梅,孙悦,赵珊珊. 行道树树种结构及健康评价的研究.吉林林业科技, 2015, 44(1): 16-20。

[22] 周宇亭. 南昌市红谷滩中心区行道树健康评价与分析 [D]. 南昌: 江西农业大学, 2012.

[23] 王可. 中国主要城市行道树树种组成与垂直结构差异分析 [D]. 哈尔滨. 东北林业大学, 2020.

[24] 王洪元. 哈尔滨、长春、沈阳行道树特征差异分析 [D]. 哈尔滨. 东北林业大学, 2018.

[25] Lv H L, Yang Y B, Zhang D, Du H J, Zhang J Y, Wang W J, He X Y. Perimeter-area ratio effects of urbanization intensity on forest characteristics, landscape patterns and their associations in Harbin City, Northeast China. Urban Ecosystems, 2019, 22(4):631-642.

[26] Ren Z B, Du Y X, He X Y, Pu R L, Zheng H F, Hu H D. Spatiotemporal pattern of urban forest leaf area index in response to rapid urbanization and urban greening. Journal of Forestry Research, 2018, 29(3):785-796.

[27] Xiao L, Wang W J, He X Y, Lv H L, Wei C H, Zhou W, Zhang B. Urban-rural and temporal differences of woody plants and bird species in Harbin city, northeastern China. Urban Forestry \& Urban Greening, 2016,20: 20-31.

[28] 王文杰, 萧路, 吕海亮, 徐海军, 张波, 周伟, 何兴元. 城市森林结构特征与生态服务功能一一以哈尔滨为例//中国植物学会八十五周 年学术年会论文摘要汇编(1993-2018). 昆明: 云南省科学技术协会, 2018: 2-2.

[29] Zhang D, Wang W J, Zheng H F, Ren Z B, Zhai C, Tang Z, Shen G Q, He X Y. Effects of urbanization intensity on forest structural-taxonomic attributes, landscape patterns and their associations in Changchun, Northeast China: Implications for urban green infrastructure planning. Ecological Indicators, 2017, 80: 286-296.

[30] Yang Y B, Lv H L, Fu Y J, He X Y, Wang W J. Associations between road density, urban forest landscapes, and structural-taxonomic attributes in northeastern china: decoupling and implications. Forests, 2019, 10(1): 58.

[31] Selmi W, Weber C, Rivière E, Blond N, Mehdi L, Nowak D. Air pollution removal by trees in public green spaces in Strasbourg city, France. Urban Forestry \& Urban Greening, 2016, 17: 192-201.

[32] Hong B, Lin B R, Qin H Q. Numerical Investigation on the Effect of Avenue Trees on PM $_{2.5}$ Dispersion in Urban Street Canyons. Atmosphere, 2017, $8(7)$. 